Supporting Information

\title{
Selective Conversion of Hemicellulose in Macroalgae E.prolifera to Rhamnose
}

Rui Zhang, ${ }^{\S}$ Yaguang Chen,${ }^{\S}$ Yingdong Zhou, ${ }^{\S}$ Dongmei Tong ${ }^{\S}$ and Changwei Hu*§

$\S$ Key Laboratory of Green Chemistry and Technology, Ministry of Education, College of Chemistry,

Sichuan University, Chengdu, Sichuan 610064, China. 
Table S1. The yield to monosaccharides under different dosage of FA

\begin{tabular}{cccc}
$\mathrm{mL}$ & Glu (\%) & Xyl (\%) & Rha(\%) \\
\hline 0 & 0 & 0 & 1.6 \\
0.4 & 0 & 2.3 & 10.4 \\
0.7 & 0 & 4.9 & 18.8 \\
0.9 & 0 & 4.4 & 16.5 \\
\hline
\end{tabular}

Reaction conditions: $140^{\circ} \mathrm{C} ; 60 \mathrm{~min} ; 3 \mathrm{~g}$ biomass

Table S2. The conversion of hemicellulose and cellulose at different reaction time

\begin{tabular}{ccc} 
Time (min) & Hemicellulose (\%) & Cellulose $(\%)$ \\
\hline 15 & 96.2 & 15.8 \\
30 & 96.9 & 25.5 \\
45 & 97.0 & 25.8 \\
60 & 97.1 & 26.4 \\
75 & 98.2 & 29.3 \\
\hline Reaction conditions: 0.7 mL FA; $160^{\circ} \mathrm{C} ; 3$ g biomass
\end{tabular}

Table S3. The yield to monosaccharides at different reaction time

\begin{tabular}{cccc}
\hline $\min$ & Glu & Xyl & Rha \\
\hline 15 & 5.1 & 8.4 & 35.8 \\
30 & 7.7 & 9.6 & 38.9 \\
45 & 10.7 & 10.2 & 40.9 \\
60 & 11.6 & 9.4 & 41.7 \\
75 & 13.8 & 9.7 & 38.1 \\
\hline
\end{tabular}

Reaction conditions: $0.7 \mathrm{~mL} \mathrm{FA} ; 160^{\circ} \mathrm{C} ; 3 \mathrm{~g}$ biomass 


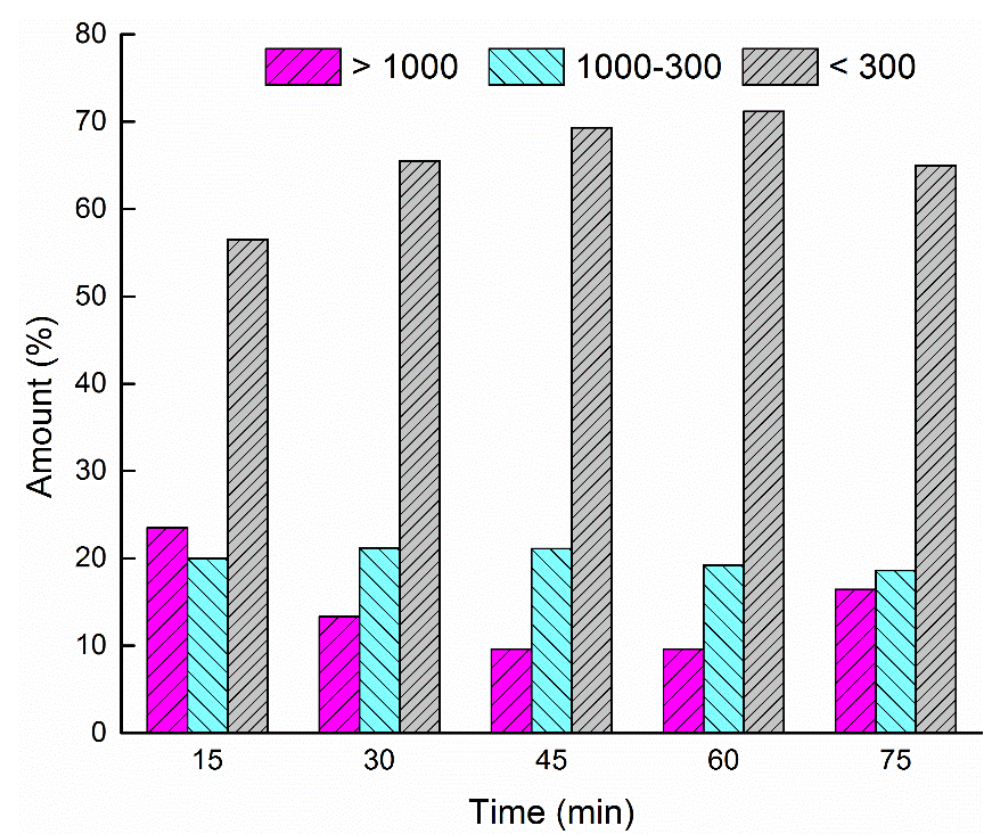

Figure S1. The distribution of molecular weight in liquid products Reaction conditions: $0.7 \mathrm{~mL} \mathrm{FA} ; 160^{\circ} \mathrm{C} ; 3 \mathrm{~g}$ biomass

Table S4. The yield to monosaccharides under different biomass loading

\begin{tabular}{cccc}
\hline Biomass loading $(\mathrm{g})$ & Glu $(\%)$ & Xyl $(\%)$ & Rha $(\%)$ \\
\hline 1 & 19.8 & 12.5 & 45.2 \\
2 & 15.7 & 11.4 & 42.6 \\
3 & 11.6 & 9.4 & 41.7 \\
4 & 6.3 & 9.2 & 35.3 \\
5 & 4.9 & 8.6 & 32.9 \\
\hline
\end{tabular}

Reaction conditions: $0.7 \mathrm{~mL} \mathrm{FA} ; 160{ }^{\circ} \mathrm{C}$; $60 \mathrm{~min}$ 